

Nigerian Journal of Technology (NIJOTECH)

Vol. 35, No. 4, October 2016, pp. $855-\mathbf{8 6 5}$

Copyright@ Faculty of Engineering, University of Nigeria, Nsukka,

Print ISSN: 0331-8443, Electronic ISSN: 2467-8821

www.nijotech.com

http://dx.doi.org/10.4314/njt.v35i4.21

\title{
FAILURE ANALYSIS AND SHOCK PROTECTION OF EXTERNAL HARD DISK DRIVE
}

\author{
H. U. Nwosu' ${ }^{1}$, C. C. Obieke' ${ }^{2}$ and A. J. Ameh ${ }^{3, *}$ \\ 1,2,3 Department of Mechanical EngineEring, University of Port Harcourt, Choba, Rivers State, NiGERIA. \\ E-mail addresses:11nazougo@yahoo.com,2nemichris@yahoo.com,3amehjohnmech@yahoo.com
}

\begin{abstract}
Technology for processing and storage of data in portable external storage hard disks has increasingly improved over the years. Currently, terabytes of data can be stored in one portable external storage hard disk drive. Storing such amount of data on a single disk on itself is a risk. Several instances of data lost by big institutions and Multinational Corporation leading to several billions of Naira annually have been reported. As the technology for storing data is improving, there is an equal need to improve on data safety and reliability. It has been estimated that hardware structural failure contributes to over $40 \%$ of reported data loss annually worldwide. This case study is aimed at failure analysis and shock protection of external hard disk drive. In order to achieve this aim, the hard disk components were assumed as a single block structure and mass-spring-damper system was used to analytically model its structural responses to free fall drop-impact shock and vibration. Secondly, the hard disk was also modeled as a beam element, which was again, subjected to impact of free fall from selected heights. The analytical results of these two mathematical models are comparable and within the limits. Then, Finite Element Analysis system was used to simulate the impact of stress on the structure of the hard disk before and after enclosing it in a padded casing. It was discovered that the padded casing absorbed shock and vibration from direct impact on the enclosed disk with a significant reduction of stress by $90 \%$. Vibration and shock protection is recommended to be designed into all such delicate engineering components and systems to mitigate occurrence of failure.
\end{abstract}

Keywords: Free fall, impact force, Shock, Vibration, Stress, Reliability, Modeling, Simulation External Hard disk drive

\section{INTRODUCTION}

Large educational institutions, corporate establishments such as banks and many critical sectors such as oil and Gas, maintain highly valuable and sensitive personnel, research, commercial and financial electronic data in their computer systems. Data are vulnerable to losses due to various reasons such as sudden damage to hardware, theft, system malfunctioning or mal-operation on the part of the operator. In such instances, the need to maintain an external data storage back-up system cannot be overemphasized and many industrial sectors are relying heavily on the external hard drives. It has been highlighted [1] that mechanical vibration and shock are two major environmental factors that negatively impact on reliability performance of engineering devices, for example, large external storage hard disks.
It has been reported that hardware failure constitutes about $40 \%$ of data loss incidents [2]while [3] highlighted overall annual cost of data loss and associated downtime, taking a holistic view of the entire Information Management, to be over a Trillion Dollars.

Over the years, the attention of many scholars and designers have been drawn to various means of reducing impact of shock and vibration on hard disk drive as it may experience very high shock levels on the order of thousands of Gravities (Gs)when dropped accidentally from a height [4]. This happens when vibration occurs especially at resonance frequencies where the displacement is amplified, which in most cases leads to components failure due to impact stress at most delicate and fragile points in the system [5]. 
The failure of brittle and ductile components of hard disk drives, due to high shock levels, has been studied [4]. In this study, fracture of glass disks (brittle material) and plastic deformation of aluminum disks (ductile material) at very high shock levels, caused by accidental drop, were investigated using finite element analysis. It was found that failure inception for both disk types occurred at the inside perimeter of the disk. Reliability of Microelectronics was investigated in the paper "Dynamic responses of Printed Circuit Board (PCB) under product-level free drop impact"[6] and it was found out that the component has the highest stress at the soldered points on the Printed Circuit board. The experimental and analytical Study of free-fall drop Impact Testing of Portable engineering Products was carried out [7] and the study highlighted that Portable products can suffer critical damage due to drop impact and thus, such load cases must be taken into account in the conceptual and detailed design phases of such products and advised the use of internal shock mounts.

In their study on Numerical Simulation of Shock Resistant Micro electromechanical systems (MEMS) [8], it was found that the packaging (chassis) played a leading role in the protection of the system against shock. On the other hand, it has been advised [9] that hardening the design and vibration isolation are viable design options to protect electronic products from accidental damage. However, with this approach, the product may end up being heavy or bulky and may not protect internal components. This is not desirable in hard disks. Vibration isolation, on the other hand, ensures controlled resilience is engineered into the system. Some other designers [10]; [11] incorporate accelerometer technology to protect computer hard disk drive against free fall impacts. When motion such as sudden drop is detected, and during the split second drop to the floor, the technology automatically locks the read / write heads on the disk drive protecting it from head crash and the loss of files.

Although many studies have been carried out, there has not been a holistic view and analysis of responses of the system structural components to free fall impacts of shock and vibration. Carried out, in this study, is the analytical presentation of impact of free fall on the performance failure of external hard disk drive structures. Implementation of shock and vibration isolation pads encased on all the 6 faces of the disk is recommended for protection of the internal structures from direct impact and failure.

\section{METHODOLOGY}

The key internal components of the external hard disk drive such as the integrated circuit board, spindle, actuator and actuator arm, platter, and the read/write head as shown in Figure 1were taken as a single structural block shown in Figure 2. The block was then subjected to free fall from 10 selected heights ranging from 0.76 meters, increasing at 0.1 meters interval, up to 1.66 meters. The responses to free fall in terms of impact force, structural displacement or deflection, and impact stress due to shock and vibration of the external hard disk, were analyzed and computed using mass-spring-damper, and the beam element models, followed with Finite Element system simulation. The data used in this case study for computation and simulation were taken mostly from the actual specifications of the external storage hard disk drive, the manufacturer's website and [12], in addition to Finite Element Analysis system parameters.



Figure 1: Major components of a computer External Hard Disk Drive

\subsection{Responses of External Hard Disk Drive to Free Fall}

It is pertinent to ask a simple question such as; what could happen to an external hard disk drive system if it is dropped from a height to hard floor surface? The simple answer could be that the system will be subjected to mechanical vibration and shock as responses to the impact of the drop. These responses could lead to system damage by cracking, bending breaking or scratches on sensitive parts. Analytically, these failures can be predicted through proper analysis of the impacted vibration, shock, force and stress. 


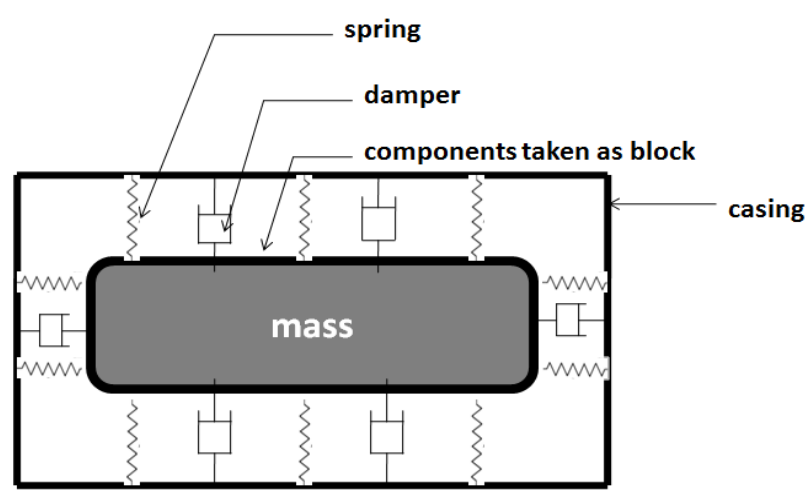

Figure 2: External storage Hard Disk Drive (HDD) modeled as a mass-spring-damper system

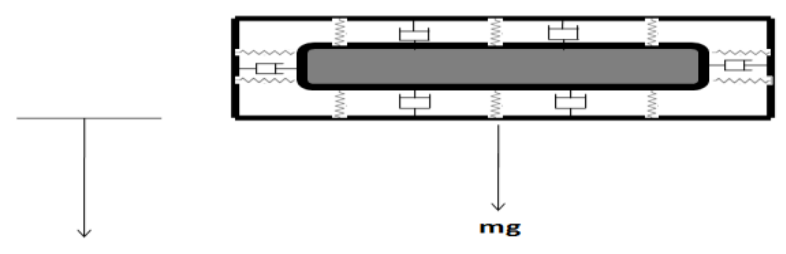

$\Delta h$

Figure 3: External storage Hard Disk model under free fall from a height of $\Delta h$.

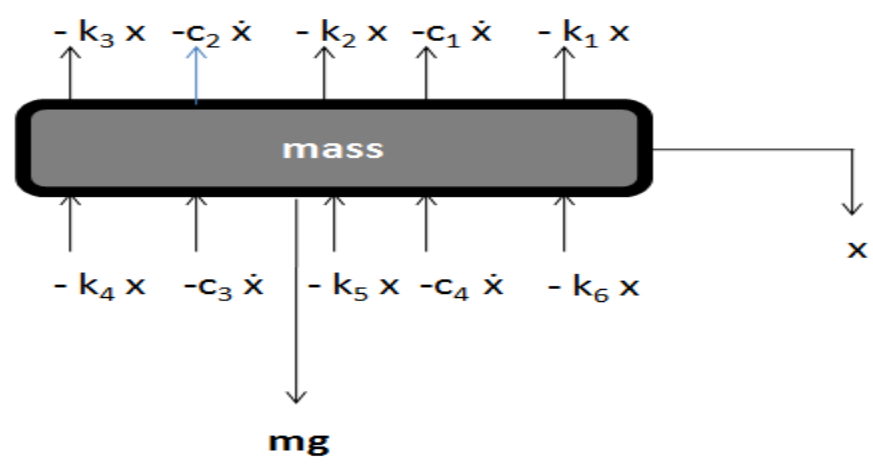

Figure 4: Free body diagram of external hard disk on hitting the ground

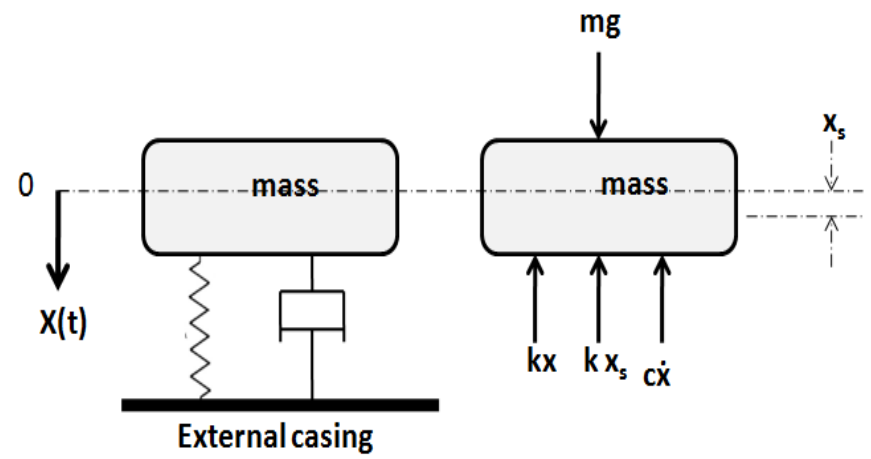

Figure 5: Spring-mass-damper system
Severe impacts can be mitigated through adequate protection of the system against damage. Key objective of this study is to analytically present the responses of an external hard disk drive to free fall to hard floor surface and make a proposal for minimizing the impacts on the system.

To deliver the above key objective, consider the external hard disk drive shown in Figure 2 where the main electronic component encased by the external structures is modeled as a mass-spring-damper system. The electronic components are taken together as a block in this study. Free fall - impact of external Hard Disk Drive dynamically set it into a vibratory mode where the excitations (input - forces) and the responses (outputs - displacement, etc) are the key variables.

Figure 4 shows the free body diagram of external storage hard disk drive in figure 3 on hitting the floor. Calculations of equivalent stiffness of the springs and damping coefficient are important for the analysis of the motion of this system. On hitting the ground, the mass, $\mathrm{m}$, is displaced by $\mathrm{x}$, thereby causing tension in springs $\mathrm{k}_{1}, \mathrm{k}_{2}$, and $\mathrm{k}_{3}$ and compression in springs $\mathrm{k}_{4}, \mathrm{k}_{5}$, and $\mathrm{k}_{6}$. The direction of the restoring forces are opposite the gravitational force on the mass, $\mathrm{m}$. Same goes for the damping forces. Springs $\mathrm{k}_{1}, \mathrm{k}_{2}$, and $\mathrm{k}_{3}$ are in parallel connection.

For simplicity, in this study, the total equivalent spring stiffness, $\mathrm{K}_{\mathrm{eqT}}=\mathrm{k}$, and the total equivalent damping coefficient, $\mathrm{C}_{\mathrm{eqT}}=\mathrm{c}$.

\subsection{Impact Force and Displacement}

Consider the mass-spring-damper system shown in Figure 5 impacted by free fall force of excitation. The mass, $\mathbf{m}$, is displaced from its equilibrium position by a distance, $\mathbf{x}$, which is a function of time, $t$.

Applying Newton's 2nd Law of Motion and summing up the forces as follows:

$$
\begin{array}{r}
F=m a=m \ddot{x}+c \dot{\mathrm{x}}+k(x+x s)-m g \\
=m \ddot{\mathrm{x}}+c \dot{\mathrm{x}}+k x=0
\end{array}
$$

Since $\mathrm{kx}_{\mathrm{s}}=\mathrm{mg}$, in (1), $\mathrm{F}$ is the Force, $\mathrm{m}$ is the mass (kg), $\mathrm{k}$ is the stiffness of the spring $(\mathrm{N} / \mathrm{m}), \mathrm{x}$ is the displacement $(\mathrm{m})$ of the mass, $\mathrm{m}$. $\mathrm{x}_{\mathrm{s}}$ is the static deflection (m) of the spring under gravity, $g$ is the acceleration due to gravity $\left(\mathrm{m} / \mathrm{s}^{2}\right), \mathrm{c}$ is the damping coefficient (Ns/m), $\ddot{\mathrm{x}}=\mathrm{a}$ is the acceleration of mass, $\mathrm{m}$, due to impacting force, $\mathrm{F}$. 
The solution of the equation of motion, equation (1) for an under damped system, according to [13] is given as:

$$
\mathrm{X}(\mathrm{t})=e^{-\xi \omega_{n} t}\left(x_{0} \cos \omega_{d} t+\frac{\dot{\mathrm{x}}_{0}+\xi \omega_{n} x_{0}}{\omega_{d}} \sin \omega_{d} t\right)
$$

An external storage hard disk drive resting on the floor surface is acted upon by a reaction force from the floor equal but in opposite direction to its weight (mg); where $\mathrm{m}$ is the mass of the hard disk and $\mathrm{g}$ is gravity. On the other hand, when the same hard disk is slightly lifted up above the floor surface and freely dropped, the impact force acting on it in this instance is no longer equal to its weight but now higher than its weight. This is due to acceleration forces that developed during impact on the floor surface.

Sudden acceleration causes shock pulse rise to its peak. It is the force of the pulse, measured in g's, that impacts on the dropped hard disk and is capable of causing damage to it. The high impact force creates stress in the system. Impact stress, in turn, creates deflection of the components, which can initiate or ultimately lead to crack and failure of the system. Maximum acceleration force can be computed with the knowledge of shock rise time and the drop height. Repeated experiment has shown that shock-rise time for striking steel mass dropped on concrete surface to be $2 \mathrm{~ms}$ [14].

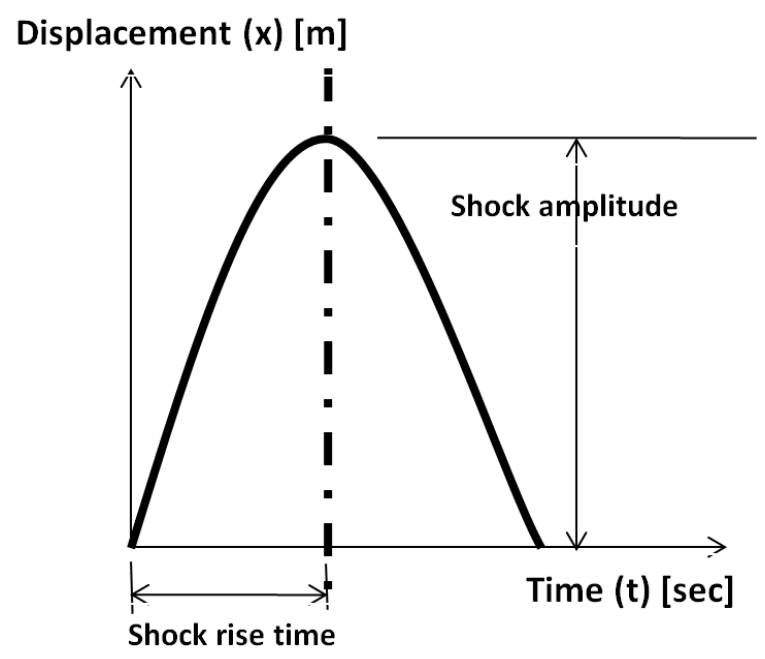

Figure 6: Half-sine wave shock response model

Half-sine wave in Figure 6 was used to model the shock impact on the external hard disk drive under free fall from a height to the floor. The sudden shock caused a displacement in the structure of the hard disk, which rose to its peak within a short time called shock rise time. Then, the shock wave quickly decayed.

To get the total impulse force over the half-sine period, the force, transmitted through the spring will be integrated over this period interval. However, since, the pulse of the impact is taken as a half-sine wave form, and half of its period is the shock-rise time and the maximum acceleration is felt at the peak of the pulse, the maximum impact force occurs during shockrise time. Analytically, the impulse is expressed in terms of the mass of the external hard disk, its drop height and acceleration due to gravity.

$$
\mathrm{I}=\mathrm{m} \sqrt{2 g \Delta h}
$$

In (3), I is the impulse ( $\mathrm{N}-\mathrm{s}), \mathrm{m}$ is the mass of the external hard disk (kg), $\mathrm{g}$ is the acceleration due to gravity $\left(\mathrm{m} / \mathrm{s}^{2}\right)$ and $\Delta \mathrm{h}$ is the drop height. From equation (3), since $\mathrm{I}=\mathrm{Fx}$ t, force (F) of impact due to impulse (I) for short time duration $(t)$ :

$$
\mathrm{F}=\frac{I}{t}=\frac{\mathrm{m} \sqrt{2 g \Delta h}}{t}
$$

Equation (4) gives the analytical expression for the force of impact on the external hard disk drive dropped from a height to floor surface. However, experimentally, the shock pulse, measured in g's is related to the drop height (inches) and shock rise time [5] as in equation (5).

$$
\mathrm{G}=\frac{72}{t} \sqrt{h}
$$

$\mathrm{G}$ is the acceleration (g), $\mathrm{t}$ is the Shock-rise time (msec), and $\mathrm{h}$ is the Drop height (in)

Applying Newton's 2nd Law of Motion:

$$
\mathrm{F}=\mathrm{ma}=\mathrm{mg}
$$

The impact force, $\mathrm{F}$, on the hard disk drive dropped from a height increases in multiple of acceleration force measured in g's. Therefore, impact force is computed from Equations (5) and (6).

$$
\mathrm{F}=\mathrm{MgG}=\mathrm{m}\left\{\mathrm{g}\left(\frac{72}{t} \sqrt{h}\right)\right\}=\mathrm{mg}\left(\frac{72}{t} \sqrt{h}\right)
$$

Notice that the experimentally derived impact force equation (7) produces identical results as the 
analytically developed force equation (4). The forces of impact due to drop from different heights create stress and strain (deflection) on the dropped hard disk drive. Induced stress and strain affect the reliability of hard disk drive, especially if it is beyond the limits the material components can bear. Hence, damage caused by shock on products are due to excessive internal stress induced by forces of inertia, which is proportional to acceleration in G's [15].

For an under damped system, the displacement (equation (2)), can be reduced to a simple form in terms of the drop height.

$$
\mathrm{x}(\mathrm{t})=\mathrm{m} \sqrt{2 g \Delta h}\left(\frac{e^{-\xi \omega_{n} t}}{m \omega_{d}} \sin \omega_{d} t\right)
$$

Equation (8) gives the displacement response of the external storage hard disk drive subjected to free fall impact.

\subsection{Impact Stress Analysis}

This study considers the impact of stress on external storage hard disk as it falls to the ground from a height under gravity. There are various possibilities as regards the face (there are 6 flat faces) of the disk that will first hit the ground. The impact of stress (force per unit area) is highest at each pointed corners and least at the 2 large flat faces. Understandably, this is due to size of contact area between the disk and the surface. The contact area at each corner is smallest when compared to the flat sides. While the loads at the corners are pointed loads, those at the flat sides are distributed loads resulting to less force per unit area and hence less stress and strain at those points. The maximum stresses at the corners are most damaging to the disk, and hence will be analyzed in this study.

In mechanics of solids, when a body is subjected to load or some measure of external force, the body gradually undergoes deformation by changing its shape or dimension [16]. However, at the point of commencement of deformation, there is an equally internal resistance to deformation by the material of the body. The body can only deform eventually if the external load is greater than the internal resistance by the body. When this happens, the body will deform elastically or plastically depending on the elastic limit for the material. Analytically, a simple direct stress $(\sigma)$ is expressed as the ratio of the applied load $(F)$ to the Area (A) over which the stress developed.

$$
\sigma=\frac{F}{A}
$$

In (9), $\sigma$ is the axial stress, $\mathrm{F}$ is the applied Load, and $\mathrm{A}$ is the area under stress. Similarly [16], observed that any part of a material that is subjected to stress will also be under strain, which is a deformation caused by stress. Analytically, simple strain $(\varepsilon)$ is the ratio of the change in length $(\delta \mathrm{L})$ to the original length $(\mathrm{L})$.

$$
\varepsilon=\frac{\delta L}{L}
$$

In (10), $\varepsilon$ is the compressive or tensile strain, $\delta \mathrm{L}$ is the change in length, and $\mathrm{L}$ is the original length. Experimentally, Robert Hook discovered that, within elastic limits, strain varies proportionally with the applied stress. The constant of proportionality is called Young's Modulus of elasticity, E. Analytically, stress $=$ constant $\mathrm{x}$ strain.

$$
\frac{\sigma}{\varepsilon}=\mathrm{E}
$$

The external hard disk drive in this study was impacted by both stress and strain after its free fall from the various experimental heights under gravity. Such impacts could deform the external casings or the electronic devices enclosed leading to crack - induced failure of the system.

Engineering components and systems such as external storage hard disk drive can fail, for example, under severe stress, exceeding its yield limit. Distortion energy theory for ductile materials predicts that for simple tension, failure occurs when the applied stress is equal to or greater than yield stress [17]. That is:

$$
\sigma \geq S_{y}
$$

This single stress, $\sigma$, is called Von Mises stress, $\sigma$. That is,

$$
\sigma^{\prime} \geq S_{y}
$$

Failure will occur if $\sigma^{\prime} \geq S_{y}$. Therefore, for design purpose, the maximum applied stress must be less than the yield stress. The external storage disk drive in this study was subjected to free fall from various heights to hard ground surface, the impacted stresses analyzed and the result validated with FE simulation. 
The maximum impacted stress was below the yield stress of the material component.

\subsection{Hard Disk Drive Structure as a Beam}

The structural components of an external storage hard disk drive, taken as a block inside its casing, is modeled here as a beam. The force of impact due to free fall of the hard disk acts uniformly on the structure of the disk and causes transverse displacement on beam-model. The Euler-Bernoulli equation for beam is used to adequately model the displacement of the disk under free fall impact.

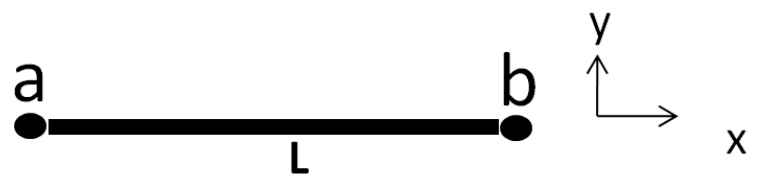

Figure 7: A beam model with length $L$ and nodes $a$ and

1. Break main domain into discrete elements (here - 2 elements used)

2. Prepare stiffness matrix for elements 1 and 2, each.

3. Combine element stiffness matrix k1 and $\mathrm{k} 2$ into a global stiffness matrix $\mathrm{K}$

4. Assemble global stiffness matrix and global force vector into system equation

5. Apply boundary conditions and solve for nodal parameters

Figure 8: Flowchart for computing transverse deflection of external hard disk drive modeled as a beam

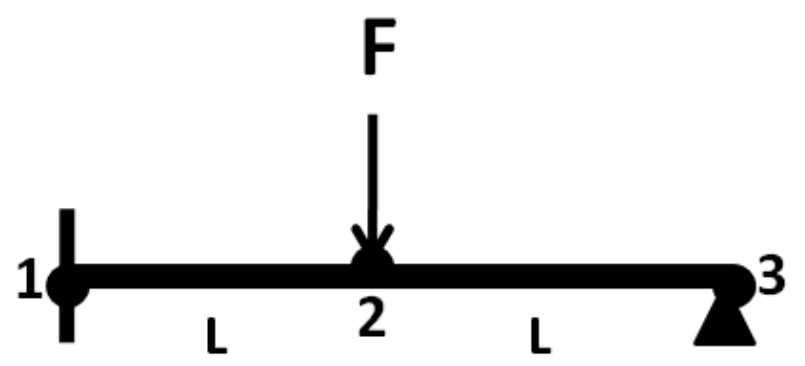

Figure 9: Discrete elements of the main beam Application of Galerkin's method on Euler-Bernoulli beam Equation resulted to finite element stiffness matrix equation [18] shown in Equation (13).

$$
\left[K^{e}\right]=\frac{E I}{l^{3}}\left[\begin{array}{ccc}
12 & 6 l-12 & 6 l \\
6 l & 4 l^{2}-6 l & 2 l \\
-12 & -6 l 12 & -6 l \\
6 l & 2 l^{2}-6 l & 4 l^{2}
\end{array}\right]
$$

\subsubsection{Summary of Procedural Steps for Computation} Consider the above beam element with 2 nodes, a and b in Figure 7. There are 2 degrees of freedom (one rotational, one transverse) at each node, making it a total of 4 degrees of freedom. For structural element with n-nodes, the global stiffness matrix, $\mathrm{K}$, is a $2 \mathrm{n} \mathrm{x}$ $2 n$ [19]. The following steps were taken to compute the transverse deflection, W, (assuming no axial deformation) of the beam using computer software. The flowchart of the steps is in Figure 8.

In summary (step 4), the global stiffness matrix [K] and global force vector $\{\mathrm{F}$ \}are assembled into force deformation system equation

$$
[K]\{d\}=\{F\}
$$

That is shown in equation (14) at the bottom of this page.

From equations (13) and (14), and known values of length (L), Young's Modulus (E) and 2nd moment of area (I) of the model beam, proceed to numerically compute the unknown variables, especially, the expected value of vertical deflection, $\mathrm{W}_{2}$, of the beam at the center (node 2) in figure 9.

\subsection{Shock Protection Principle}

The schematic diagram in Figure 10 illustrates the principle of vibration isolation of external hard disk drive . In this study, all the internal components were taken together as a block. The external casing enclosing all the internal components was considered as structure. In-between the casing and the internal components structure is a pad made of ethylene-vinylacetate (EVA) designed to isolate or absorb effects of vibration / shock from impacting on the critical electronic components enclosed. This shock protection mounts are in between the outer and the inner surfaces of the 6 flat sides of the disk drive, thereby suspending the entire inner structure. This enabled absorption of destructive shock and vibration from reaching the inner fragile components. The theoretical analysis of the finite element computation of the forces, displacement and spring stiffness that will enable optimization of design parameters for isolation of vibration from impacting on external hard disk drive follows. Two spring element system extracted from Figure 10 is shown in Figure 11. 


$$
\frac{E I}{l^{3}}\left[\begin{array}{cccccc}
k_{11} & k_{12} & -k_{13} & k_{14} & 0 & 0 \\
k_{21} & k_{22} & k_{23} & -k_{24} & 0 & 0 \\
-k_{31} & -k_{32} & k_{33}+k_{11}-\left(k_{34}+k_{12}\right) & -k_{13} & k_{14} \\
k_{41} & k_{42} & -\left(k_{43} k_{21}\right) & k_{44}+k_{22} & -k_{23} & k_{24} \\
0 & 0 & -k_{31} & -k_{32} & k_{33} & -k_{34} \\
0 & 0 & k_{41} & k_{42} & -k_{43} & k_{44}
\end{array}\right]\left\{\begin{array}{c}
w_{1} \\
\theta_{1} \\
w_{2} \\
\theta_{2} \\
w_{3} \\
\theta_{3}
\end{array}\right\}=\left\{\begin{array}{c}
F_{1} \\
M_{1} \\
F_{2} \\
M_{2} \\
F_{3} \\
M_{3}
\end{array}\right\}
$$

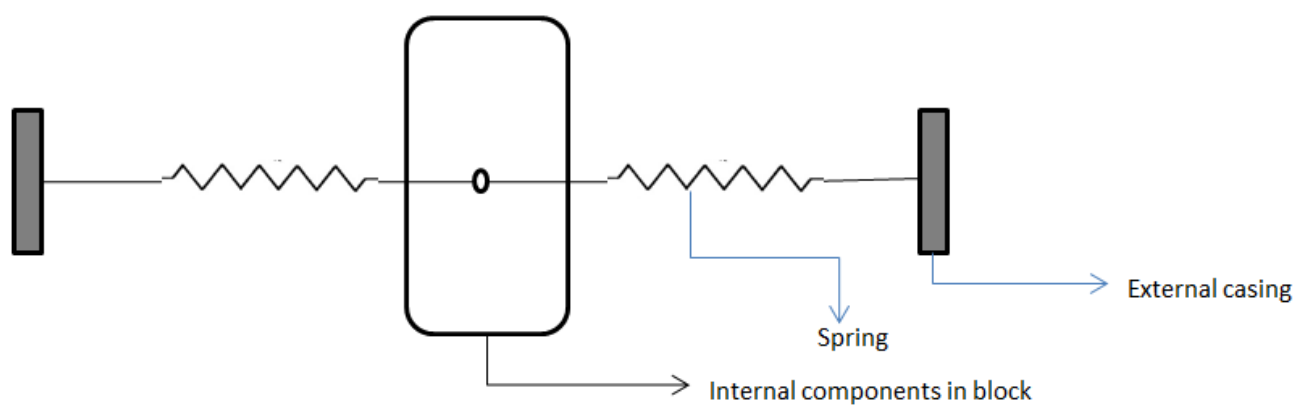

Figure 10: Illustration of vibration isolation principle

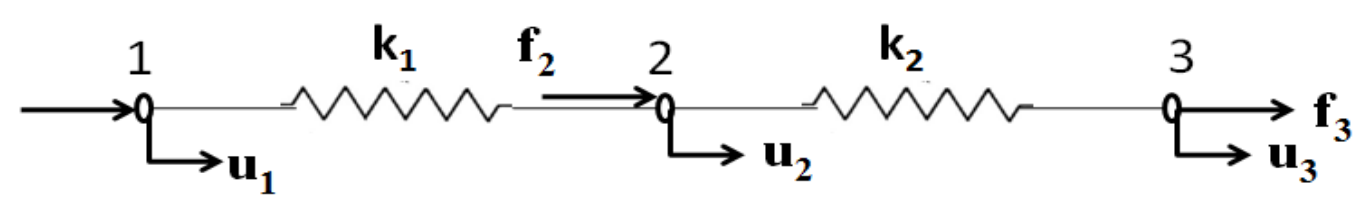

Figure 11: Detailled forces on springs (pads) on both sides of the block of internal components of hard disk.

The force impacting on the pads modeled as spring above can be expressed in terms of its stiffness matrix and the displacement, $\mathrm{d}$, as:

$$
\left[\begin{array}{ccc}
k_{1} & -k_{1} & 0 \\
-k_{1} & k_{2}+k_{2} & -k_{2} \\
0 & -k_{2} & k_{2}
\end{array}\right]\left\{\begin{array}{l}
u_{1} \\
u_{2} \\
u_{3}
\end{array}\right\}=\left\{\begin{array}{l}
f_{1} \\
f_{2} \\
f_{3}
\end{array}\right\}
$$

In general term,

$$
\mathrm{Kd}=\mathrm{F}
$$

In (15), $\mathrm{U}$ is element nodal displacement vector, $\mathrm{F}$ is the global nodal force vector, $\mathrm{d}$ is called the global nodal displacement vector, and $\mathrm{K}$ is called the global stiffness matrix for the spring system in Figure 11. Design optimization can then be carried out as required with the specification of force, stiffness or the displacement to achieve desired performance results.

\subsection{External Hard Disk Drive Failure Modes, Prediction and Mitigation}

External hard disk drive failure occurs when malfunctioning is noticed and the information stored cannot be located. Failures can occur either when the hard disk drive is in operation or in non-operation mode. External factors such as mechanical impact can lead to varieties of failures of hard disk. Damage can occur on major components of hard disk drive during shipping and handling activities. Excessive mechanical shock, stresses from both internal and external sources have potential to cause the recording head to go off track. In the course of write operations, this could result in data loss or data on the adjacent track can be overwritten [20].

The following are some of the failure modes that can be caused by free fall of hard disk drive in this case study. These are mainly structural failures due to shock impact, which usually extends to other modes of electrical / electronic failures.

1. Read / write head failure - Head crashing into the platter or distortion of flying height.

2. Deformation of actuator arm

3. Crack of integrated circuit board

4. Crack of platters surfaces

5. Deformation of base plate

Structural material failures occur, for ductile materials, if the applied stress is equal to or more than the yield stress of the material of the hard disk drive component, and for brittle materials, if the principal stress equals or greater than the material ultimate strength in compression or in tension [17] 
To mitigate these likely failure modes of external hard disk drive, it is proposed that a carefully design-in vibration/shock protection mounts should be incorporated on all the 6 sides of the external storage hard disk drive (figure 2) such that the components are suspended in between the isolation mounts. The shock mounts should be screwed in between designed double casing enclosing the internal components. This will significantly reduce damaging stress from impacting directly on the component system.

\section{RESULTS AND DISCUSSION}

The results of the case study on Analysis of impact of free fall on reliability of external hard disk drive is presented and discussed in this section. Maximum displacement of the system for each of the 10 selected drop heights were computed. Calculated impact force value for each of the 10 selected drop heights was used to, in turn, compute the values for the respective impact stresses. Finite Element system simulation of



Figure 12: Displacement response of external hard disk drive against free fall drop heights using Beam and Mass-springdamper Model analysis compared

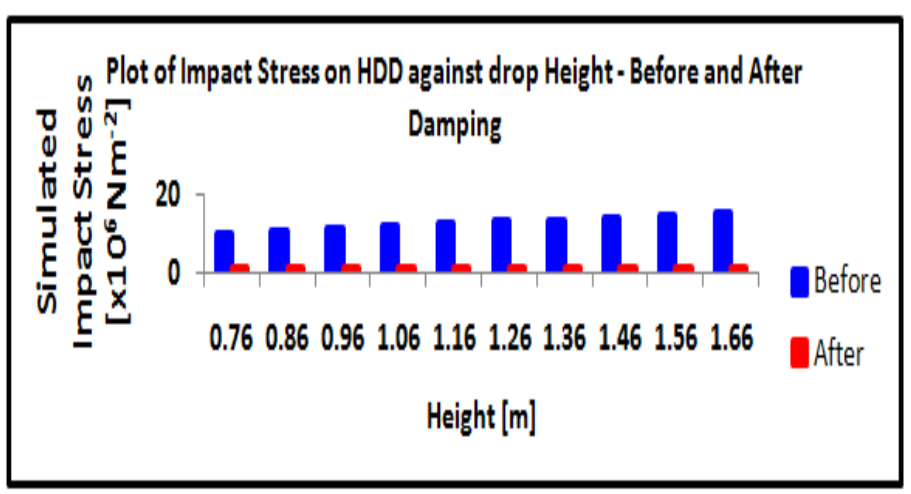

Figure 14: Simulated maximum impact Stress values on external storage hard disk drive dropped from selected heights before and after vibration protection pads encased impact stress for each of the drop heights was carried out. Results are shown in the figures 12-19.

\subsection{Discussion}

External storage hard disk drive is a delicate engineering component and system. Its performance reliability can be affected if subjected to free fall dropimpact under gravity to a hard surface. The impact force initiated excitation that set the system to vibrate with a decaying amplitude as shown in Figure 16. The force of impact acted on the structure of the system and created impact stress on it. Mass-spring-damper, and the beam element models were used to analyze the displacement/deflection response of the external storage hard disk drive and the results compared showed that amplitudes increased as the selected heights in this case study increased as showed in Figure 12 .

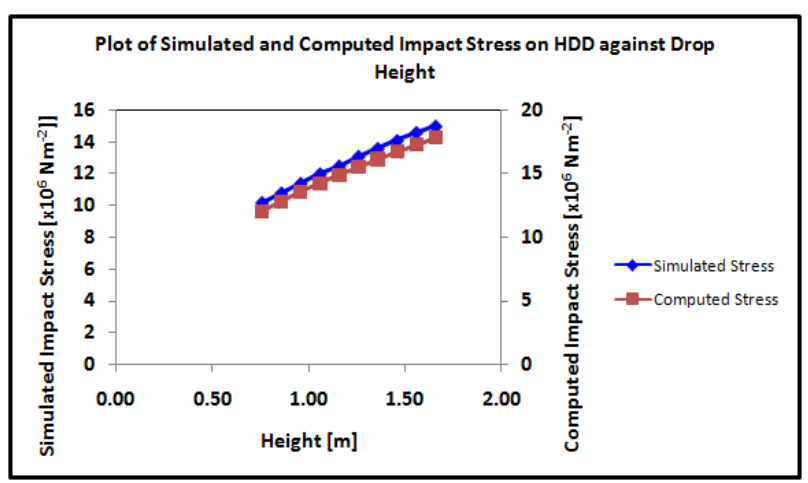

Figure 13: Computed maximum impact Stress values on external storage hard disk drive dropped from selected heights versus Finite Element Simulated values

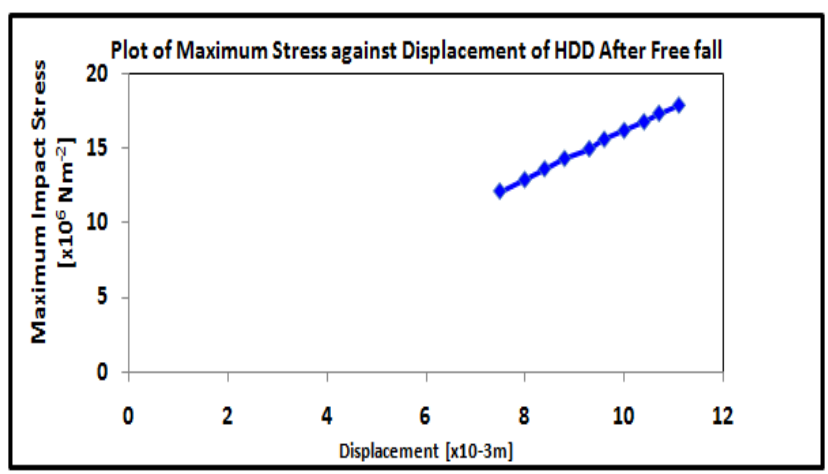

Figure 15: Maximum impact Stress values on external storage hard disk drive dropped from selected heights against displacement response 


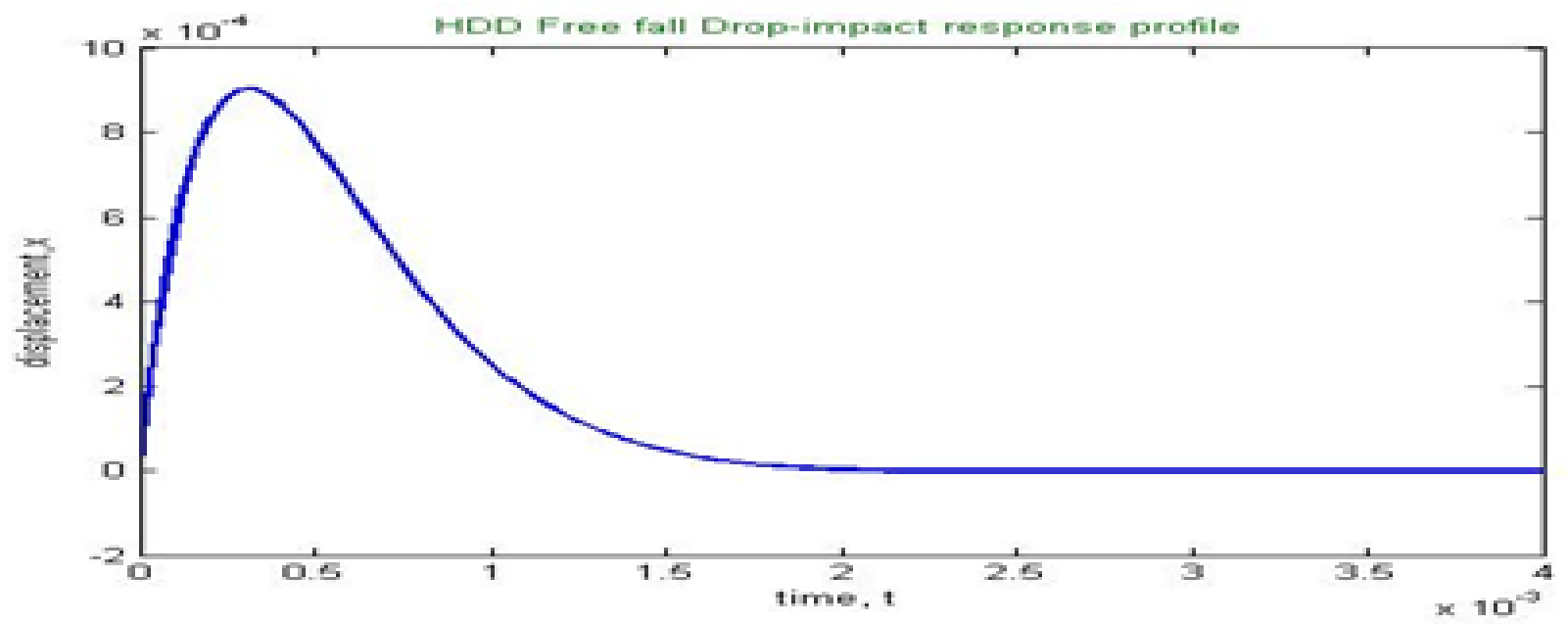

Figure 16: Half-sine shock response profile of external storage disk drive dropped from a selected height.

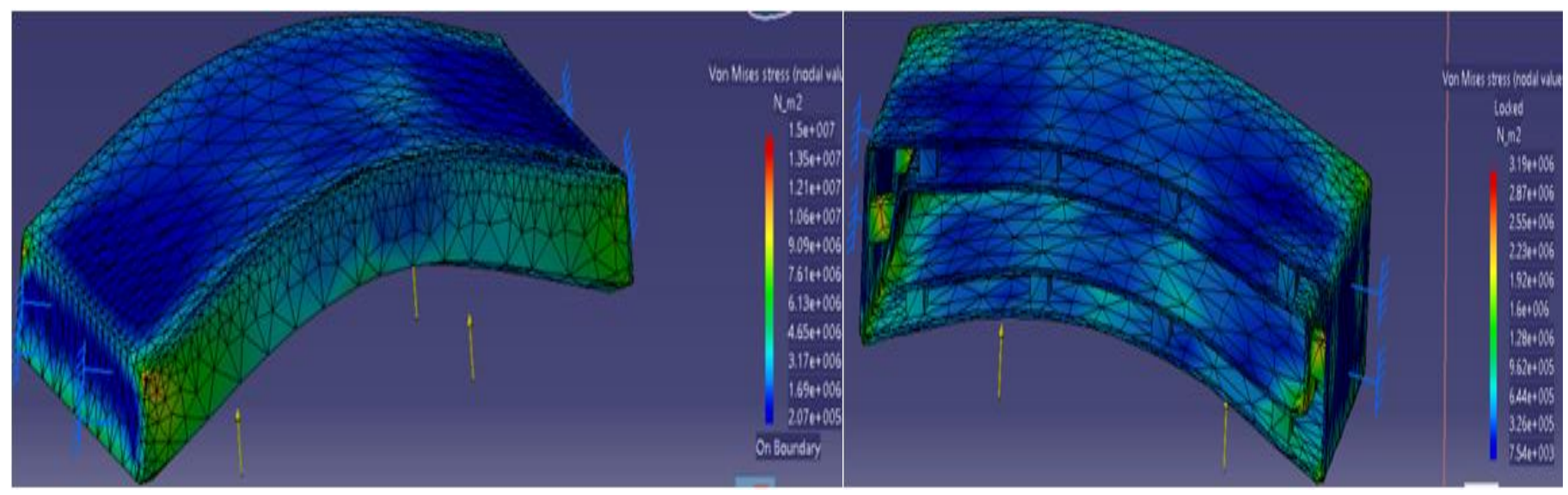

(a) without vibration protection pad

(b) with vibration protection pad

Figure 17(a) and (b): Output of Finite Element Analysis system simulation of impact stress on external storage disk drive dropped from a height of $1.66 \mathrm{~m}$.

The implication of these results is that the resultant impact strain can cause disk failure by stressing the material of the component beyond its limit. The simulated maximum impact stress on the system compared well with the analytical results as shown in Figure 13. The result showed that the higher the free fall height, the higher the impact stress. The stress levels analyzed at drop heights up to maximum of 1.66 meters are all below the yield strength of the external storage disk drive material component. Therefore, no damage is expected on the disk dropped from a maximum of 1.66 meters, which is about the level of shelves commonly used for disk storage in offices. However, at a height of 1.76 meters, high stress concentration of $18.364 \times 106 \mathrm{Nm}-2$, which is slightly above yield stress of $18 \times 106 \mathrm{Nm}-2$, initiated signs of overstressed material at the sharp edges. Further increase in drop heights increased stress concentration at the edges while propagating it to the rest part of the component. At a clear height of 3 meters, the resulting impact stress of $23.975 \times 106$ $\mathrm{Nm}-2$ is well above the yield stress. Severe damages due to cracks, which could impact on the integrity of the component or even outright failure, are inevitable at heights from 1.76 meters and above.

Though impact stresses may not show visible damage on the disk, it could initiate process which could trigger structural failure in the near future. To mitigate this likely event, external storage hard disk drive in this study was enclosed in a padded case. The material, Ethylene-Vinyl-Acetate (EVA), of the selected design pad has vibration absorbing property [12]. The result of finite element simulation of impact stress on the disk before and after the disk was enclosed in a padded case showed that maximum impact stress dropped by almost $90 \%$ on the average as shown in Figure 14.Figures 17(a) and (b) showed the output of Finite Element Analysis system simulation of impact stress on external storage disk drive dropped from a height of $1.66 \mathrm{~m}$. The rest output results for the 
remaining simulated free fall height levels and their respective stresses were also analyzed as plotted in figure 14 .

\section{CONCLUSION}

This case study was focused on analysis of structural reliability of external storage hard disk drive subjected to free fall drop-impact stress. The key component parts making up the hard disk drive as shown in this study, figure 1, have delicate structures, which were impacted by stress on hitting floor surface. The vibration absorbing pad acted as a damper and significantly reduced the impact stress from directly impacting on the delicate external storage hard disk drive component, thereby protected it from the risk of crack-induced failure due to dropimpact on hard surfaces. It is recommended that adequate vibration and shock protection be designedin to external storage hard disk drive system right from its conceptual design stage to ensure system reliability even in hash stress, mechanical shock and vibration environments. Though this case study is on external storage hard disk drive, it is also applicable to other portable and delicate Micro electromechanical systems (MEMS) such as accelerometers, cell phones, media players, digital cameras, etc.

\section{REFERENCES}

[1] Yoo, S. W.: Vibration Isolation and Shock Protection for MEMS. A Dissertation submitted in partial fulfillment of the requirements for the degree of Doctor of Philosophy (Electrical Engineering). Ann Arbor: University of Michigan. 2009.

[2] Smith, D. M. The Cost of Lost Data - The importance of investing in that "ounce of prevention". Graziadio Business Review. [online] 6 (3). Available from: http://gbr.pepperdine.edu/2010/08/the-cost-oflost-data/. [Accessed: 24th June 2015], 2003.

[3] Hopkinton, M.: Press Release - Over \$1.7 Trillion Lost Per Year from Data Loss and Downtime According to Global IT Study. EMC News. [online] 2nd December 2014. Available from: http://www.emc.com/about/news/press/2014/20 141202-01.htm. [Accessed: 24th June 2015]. 2014.

[4] Xu, J., Etsion, I. \&Talke, F. E. Failure of Brittle and Ductile Hard Disks Due to High Shock Levels. Journal of Mechanical Design, Vol. 131 (11). pp. 1 8, 2009.
[5] Nwosu, H. U. Dealing with Shock and Vibration in Electronic Equipment. NSE Technical Transactions 40(1). pp. 35-46, 2005.

[6] Yu, D., Kwak, J. B., Park, S. \& Lee, J. Dynamic responses of PCB under product-level free drop impact, Microelectronics Reliability. 50. p. 10281038. 2010.

[7] Tempelman, E., Dwaikat, M. M. S. \& Spitas, C. Experimental and Analytical Study of Free-Fall Drop Impact Testing of Portable Products. Experimental Mechanics 52. pp. 1385-1395. 2012.

[8] Lu, Y. B., Cheng, Y. S. Sun, Y. C. Numerical Simulation of Shock Resistant Microsystems (MEMS). Modern Mechanical Engineering. 4. pp. 119-124, 2014.

[9] Fraser, J. W. \& Gureghian, R. S. Controlling shock and vibration in electronic products. Mechanical Engineering 115 (12). pp. 82-84, 1993.

[10] Mitchell, R. L Airbag for Laptop. Computerworld [online] 6th July 2005. Available from: ttp://www.computerworld.com/article/2482429/c omputer-hardware/airbags-for-laptops.html.

[Accessed: 3rd July 2015].

[11] Smith, T. IBM debuts hard drive 'airbag' crash protection. [online] 6th October 2003. Available from: http://www.theregister.co.uk/2003/10/06 /ibm_debuts_hard_drive_airbag/. [Accessed: 24th June 2015].

[12] Ashby, M. F. Materials Selection in Mechanical Design, Third Edition, Burlington: BurtherwoothHeinmann. (2005).

[13] Rao, S. S.: Mechanical Vibrations, Fifth edition, Upper Saddle: Prentice Hall, 2011.

[14] Nwosu, H. U. Designing Computer Hard Disk Drives for Mechanical Shock and Vibration. Nigerian Journal of Industrial and Systems Studies, 2(3). pp. 47-62, 2003.

[15] Nwosu, H. U. Procedure for Determining Damage Boundary for Hard Disk Drive Fragility Assessment. CEM, 1(1). pp. 31-38. (2004).

[16] Rajput, E. R. K. Strength of Materials [Mechanics of Solid] Revised Edition, Ram Nagar, New Delhi: S. Chand \& Company Ltd. (2006).

[17] Budynas, R. G. and Nisbett, J. K.: Shigley's Mechanical Engineering Design, Eighth Edition, USA: McGraw-Hill, 2008. 
[18] Kwon, Y. W. and Bang, H. The Finite Element Method using MATLAB, Washington, D. C., CRC Press, 1997.

[19] Katta, P.: MATLAB Guide to Finite Elements - An Interactive Approach, Second Edition, New York: Springer, 2008.
[20] Nwosu, H. U.: Structural Dynamics Analysis of a Winchester $5^{1 / 4^{\prime \prime}}$ Rigid Disk Drive. Journal of Engineering Computing and Applications, pp. 18-36. 1989. 